N.N.W. Sunset-glow intersected by five horizontal dark cloudstreaks in the west. On the 2 nd inst., at 4.20 p.m., five cumulostrati were visible in the west, separated by parallel and horizontal orange-coloured bands. Above these were numerous (probably twenty) delicate dark lines traversing -also horizontallythe upper roseate after-glow. On the Ioth and IIth inst., somewhat similar phenomena were visible here. On the $15^{\text {th }}$ inst., with a light southerly air, eleven cloud-bands were seen by me at $4.30 \mathrm{p} . \mathrm{m}$. In this case only, they were not parallel to the sea-line, but followed the direction of the west-north-west horizon. I have seen the same appearances once or twice since the last date. The above phenomena are new to me, and I have not met with any detailed account of them elsewhere. I have therefore ventured to address you on the subject. Can these cloud-streaks represent stratified air-dust in the upper regions of our atmosphere?

Hove, Brighton, December 26

\section{Iridescent Clouds}

THERE was a very striking display of iridescent clouds this afternoon. I noticed it first at about 3.40 p.m. The prismatic colours were pretty strongly marked, and the intense pearly brilliance of the delicate cirri was most striking. It is still visible (4.40 p.m.), though, of course, its lustre is much diminished. A gale is blowing from the west, and there has been an orange after-glow. Similar phenomena were described in your columns about this time last year. They were well seen in this part of the country.

Earsdon, Newcastle-on-Tyne, December 28

YESTERDAY, clouds very similar to those seen a year ago made their appearance, and there were a few of them again this morning. I first noticed them at II.30 a.m., and they were extremely magnificent after sunset, showing three or four spectra of colour, and they were especially striking about 4. ro p.m., when they appeared very bright against the purple glow of the sky. Their chief difference from the clouds last December was that they were not bounded by straight lines, and that there was no special amount of blue in the colouring, as was usually the case a year ago. The chief colours were pink and green.

Sunderland, December 29

T W. BACKHOUSE

\section{Ventilation}

IN reply to the query of J. F. Tennant, there can be no doubt that the cause of the failure of the ceiling ventilators is a deficiency of fresh-air supply to the room. An ordinary chimney with a fire will, if unchecked, draw an amount of cold air into the room which would make the temperature about the same as that of the outside air, and without enormous volumes of warmed air it is, I think, impossible to expect any service whatever from the system of ventilation from ceiling-flues, as recommended by the writer of the article referred to. Since writing my first letter I have seen a regenerator lamp attached to one of these ceilingflues, and the down-draught was so strong and persistent as to reverse the natural current of the lamp, rendering its use impossible. The air-inlet to my own rooms consists of a channel in the wall of every room opening into ten one-inch holes at the fireplace, but this, of course, is utterly inadequate to supply onetenth of the air required by the flue, and the ventilator and the ventilating-shaft supplement this supply by working the wrong way.

Warrington

THOS. FletcheR

A VERY common soluce of trouble with respect to ventilation is the absence of any arrangement for the supply of air to fires. So long as a fire draws on the general atmosphere of the room it is supposed to warm for its supply of oxygen, there must be the "draughts" so often complained of, and people are warm on the side next the fire, and cold on the other. I should suppose this is what happens in Mr. Fletcher's case, described in his letter in NATURE (pp. I53-4). If so, there is simply a sort of "tug-of-war" between the longer chimney-flue and the shorter ventilation flue, with the additional advantage on the side of the former that the column of air ascending the chimney is neces- sarily much warmer than that which should ascend the ventilation flue. If, however, Mr. Fletcher will have a couple of holes bored in his floor, one on each side of the fireplace, so as to supply air directly to the fire, the "pull" of the fire on the air of the room will cease, the room will be warmer, and his ventilation flue should work satisfactorily. I warm thoroughly a room with considerably over 2000 square feet of floor area by means of three small stoves. When first used the stoves were inefficient, as there was a draught all round each towards it. A common rain-water pipe "bend," inserted in the floor immediately in front of the aperture of each stove for admitting the air-supply, stopped the draughts, and at least doubled the efficiency of the stoves as warmers. With the help of Tobin tubes there is now a gentle current of warmer air from each stove. The heated and vitiated air escapes through ventilators fixed in the ridge of the roof.

Eldun, Bishop Auckland, December 23

\section{Friction and Molecular Structure}

IN your number of December I 7 (p. I 54 ) is a letter signed by $\mathrm{Mr}$. E. Geoghegan, referring to the effect of moderate friction on the molecular structure of glass lamp-chimneys. This I have very frequently observed, and it would be very interesting to have suggestions as to its cause and means of prevention. I often read under one of Sugg's Argand gas-burners, the chimney of which almost invariably breaks on first heating after cleaning. First of all, washing was tried, to remove the mottled milky stain which forms on the glass, and then rubbing with a silk cloth or cotton rubber, but there does not seem to be much difference in the result, as the glasses, the best I can obtain, generally treak.

Bramhope, Old Charlton, Kent, December 25

\section{The Longevity of Insects}

WITH reference to the longevity of insects, it is worth while to record that we kept a ladybird from the September of one year to the September of the following. She was a handsome specimen of the seven-spotted ladybird, and her eggs, which were laid in the winter, after passing through the miniature crocodile stage, produced perfect insects in February. It is curious to watch the imago emerging from its dusky case; at first no spots are visible on its buttercup-yellow "shards," which contrast strongly with the jet-black legs and underneath; but in a very few hours the first brilliancy has gone, the spots appear faintly, and in a few days the final red with the black spots is established.

December 28

\section{SOUTH AMERICAN BIRD-MUSIC}

M R. BURROUGHS, an American naturalist, in his "Impressions of some British Song Birds," has said :- "Many of the American songsters are shy woodbirds, seldom seen or heard near the habitations of men, while nearly all the British birds are semi-domesticated, and sing in the garden and orchard. This fact, I had said, in connection with their more soft and plaintive voices, made our song-birds seen less to a foreign traveller than his own." These words apply with much greater force to the birds of South America, the species being much more numerous and less well known than in the northern portion of the continent; while the true songsters are relatively fewer, owing to the presence of several large songless families, such as the tyrants, hummingbirds, and others.

The South American songsters certainly do not, like those of Europe, mass themselves about the habitations of men, to sing there as if sweet voices were given to them solely for the delectation of human listeners; they are pre-eminently birds of the wild forest, the marsh, and the savannah; and the ornithologist or collector from Europe, whose principal object is to make a large collection, has 